\title{
OPEN Life expectancy estimations and determinants of return to work among cancer survivors over a 7-year period
}

\author{
Wei-Liang Chen ${ }^{1,2,3,8}$, Yuan-Yuei Chen ${ }^{4,5}$, Wei-Te Wu ${ }^{6}$, Ching-Liang Ho7 \& \\ Chung-Ching Wang ${ }^{1,2 \bowtie}$
}

Due to advances in medical science and technology, the number of cancer survivors continues to increase. The workplace needs and employment difficulties cancer survivors face after treatment need to be addressed to protect these individuals' right to work and to maintain the overall labor force of the country. We conducted a retrospective cohort study with a follow-up period from 2004 to 2010. All data analyzed in the study were obtained from the Labor Insurance Database, the Taiwan Cancer Registry of the Ministry of Health and Welfare, and the National Health Insurance Research Database. The relationships between risk factors and the presence of returning to work were analyzed by a Cox proportional hazard model. The survival rates of patients with different cancer stages were evaluated using Kaplan-Meier survival analysis. Among the employees with an initial diagnosis of cancer, $70.4 \%$ remained employed through 1 year after the diagnosis, accounting for $83.4 \%$ of all cancer survivors; only $51.1 \%$ remained employed through 5 years after the diagnosis, accounting for $78.7 \%$ of all cancer survivors, a notable decrease. Age, gender, salary, treatment method, company size, and cancer stage were the factors that affected whether employees could return to work or not. The long-term survival of people diagnosed with cancer depends on their chances of returning to work. Strengthening existing return-to-work policies and assisting cancer survivors with returning to work after the treatment should be priorities for protecting these individuals' right to work and for maintaining the overall labor force.

The occupational safety and health of employees is the foundation of social stability. The protection of employee's lives and improvements of their physical and mental health are critical for the stable development of society. With rapid industrial development, Taiwan's employed population has increased for many years. According to the Taiwan Occupational Safety and Health Institute's analysis of the causes of death between 2003 and 2008, malignant tumors were the leading cause of death among employees in Taiwan, with a standardized death rate of 47.0 per 100,000 people $^{1}$. In Taiwan, pulmonary cancer has the highest mortality rate, followed by hepatic cancer, colorectal cancer, female breast cancer, gastric cancer, oral cancer, prostate cancer, cervical cancer, esophageal cancer, and pancreatic cancer. Among insured employees in Taiwan, liver cancer has the highest mortality rate,

\footnotetext{
${ }^{1}$ Division of Family Medicine, Department of Family and Community Medicine, Tri-Service General Hospital, and School of Medicine, National Defense Medical Center, Taipei, Taiwan, Republic of China. ${ }^{2}$ Division of Occupational Medicine, Department of Family Medicine and Community Medicine, Tri-Service General Hospital, National Defense Medical Center, Number 325, Section 2, Chang-gong Rd, Nei-Hu District, 114, Taipei, Taiwan, Republic of China. ${ }^{3}$ Division of Geriatric Medicine, Department of Family and Community Medicine, Tri-Service General Hospital, and School of Medicine, National Defense Medical Center, Taipei, Taiwan, Republic of China. ${ }^{4}$ Department of Pathology, Tri-Service General Hospital Songshan Branch, and School of Medicine, National Defense Medical Center, Taipei, Taiwan, Republic of China. ${ }^{5}$ Department of Pathology, Tri-Service General Hospital, and School of Medicine, National Defense Medical Center, Taipei, Taiwan, Republic of China. ${ }^{6}$ National Institute of Environmental Health Sciences, National Health Research Institutes, Miaoli, Taiwan, Republic of China. ${ }^{7}$ Division of Hematology/Oncology, Department of Medicine, Tri-Service General Hospital, and School of Medicine, National Defense Medical Center, Taipei, Taiwan, Republic of China. ${ }^{8}$ Department of Biochemistry, National Defense Medical Center, Taipei, Taiwan, Republic of China. ${ }^{\boxplus}$ email: bigching@gmail.com
} 
followed by pulmonary cancer, oral cancer, colorectal cancer, female breast cancer, esophageal cancer, gastric cancer, nasopharyngeal carcinoma, pancreatic cancer, and leukemia.

Because the incidence and prevalence of cancer has persistently increased in the past few years, along with the cure rates, cancer survivors are becoming increasingly more common in the workplace ${ }^{2}$. In addition to career interruptions and substantial medical expenses, a cancer diagnosis alone is a source of stress. These are all important factors that impact health-related quality of life. Most cancers affect patients at physical, mental and spiritual levels and even affect their functional and occupational abilities.

According to studies conducted in other countries, most employees choose to continue working during cancer treatment ${ }^{3}$. However, their employment was still interrupted by the treatment and its side effects, impacting their work efficiency. Cancer survivors after treatment have physiological, psychological, and social adaptation issues and are unable to immediately resume a full workload or work abilities similar to those before contacting the disease. According to a systemic review that included studies from Europe and Asia, the overall rate of returning to work estimated at was $72 \%{ }^{4}$. Another cross-sectional study showed that $74 \%$ of breast cancer survivors expressed a desire to return work, but only $54 \%$ of these breast cancer survivors did so ${ }^{5}$. Cancer survivors have a high unemployment risk and may have considerable physical, psychological and social problems, such as fatigue, pain, cognitive decline, anxiety and depression, which may be temporary but may also persist and become chronic ${ }^{6}$. Current studies have noted that multiple comorbidities, poor health conditions, treatment complications, persistent pain, and depressive mood are important risk factors for unemployment ${ }^{7}$. After cancer treatment, many patients will undergo changes in work status, have taken prolonged sick leaves, and experience unemployment and various other issues, causing their chosen careers to end ${ }^{8}$. Therefore, evaluation and re-employment services for cancer survivors are necessary for the transition of these individuals from the disease state to the workplace.

Work disability places a great burden on individuals, the economy and public health. Therefore, successfully predicting and preventing work disability is an important research subject. Job participation can be regarded as an affirmation of self-worth, identity and social roles ${ }^{9}$. Returning to work or re-employment is very important for cancer survivors, their families and society. Most cancer survivors regard returning to work as a symbol of full recovery and regaining a normal life. Returning to work can also help maintain family income, self-esteem, sense of meaning, and health ${ }^{10}$. If unable to return to work, patients may be deprived of personal social contact and well-being ${ }^{11}$. Mehnert et al. summarized several studies and indicated that approximately $63.5 \%$ of cancer survivors will try to return to work after completing treatment; 6 months after diagnosis, approximately $40 \%$ of cancer survivors returned to work or kept working while receiving treatment (between 24 and $72 \%$ ); 12 months after diagnosis, approximately $62 \%$ of cancer survivors returned to work or continued to work during treatment (between 50 and $81 \%$ ); 18 months after diagnosis, approximately $73 \%$ of cancer survivors returned to the work or continued to work during treatment (between 64 and 82\%); and 24 months after diagnosis, approximately $89 \%$ of cancer survivors returned to work or continued to work during treatment (between 84 and $94 \%)^{12}$. From the above studies, we found that due to different cancer characteristics and treatment guidelines, a certain proportion of people cannot return to their previous work; therefore, identifying risk factors, identifying highrisk groups, educating employers and employees, and applying existing return-to-work policies to assist cancer survivors are imminently needed.

Currently, there is still a lack of large-scale long-term follow-up studies on the return to work of cancer survivors in Taiwan. Therefore, the purpose of this study was to establish a long-term cohort database of cancer survivors based on the National Health Insurance Research Database and to gain an in-depth understanding of the basic characteristics of and RTW situation of cancer survivors to determine the factors that hinder their returning to work. This study can be used as a reference for employment services of the state, appropriate employment counseling and assisting unemployed cancer survivors in returning to work.

\section{Methods}

The period investigated in this study was from 2004 to 2010, a total of 7 years, and the Labor Insurance Database was used as the main source of information. Labor insurance established by Taiwan government is a compulsory program for workers above 15 years and below 65 years of age intended to protect their rights and interests. First, we identified all employees covered by labor insurance using "Insured File" and "Enterprise File" in the Labor Insurance Database. All selected employee data included salary, company size, county and city where the company is located, changes in insurance, effective date of insurance, employment category and other related information. Combined with the Taiwan Cancer Registry, we identified employees with an initial diagnosis of cancer, thus establishing the cohort for this study. There were 136,342 eligible participants enrolled in this cohort study, including 69,619 patients returning to work and 66,723 patients not returning to work. In addition, we used the National Health Insurance Research Database to obtain inpatient and outpatient records, comorbidities, and cancer-related treatments (including surgery, radiation therapy, chemotherapy, and hormone therapy) as well as prediction of death for each case. This study was reviewed and approved by the Institutional Review Board of Tri-Service General Hospital.

Covariables. Relevant variables were collected from the databases for the purpose of the study. Personal characteristics included age, gender, monthly salary (divided into $\leq 28,800,28,800-38,200$, and $>38,200$ New Taiwan Dollars), medical care accessibility (divided into North, Middle, South, and East according to health insurance subdivision) and employment category. Health status included a medical history of major chronic diseases in the year prior to the cancer diagnosis (according to the International Classification of Diseases 9th edition, ICD-9). The clinical comorbidities included disorders of lipid metabolism (ICD-9-CM codes, 272), alcohol abuse (ICD-9-CM codes, 265.2, 291.1-291.3, 291.5-291.9, 303.0, 303.9, 305.0, 357.5, 425.5, 535.3, 571.0- 
571.3, 980.x, V11.3), cerebrovascular diseases (ICD-9-CM codes, 362.34, 430.x-438.x), chronic pulmonary diseases (ICD-9-CM codes, 416.8, 416.9, 490.x-505.x, 506.4, 508.1, 508.8), peptic ulcer diseases (ICD-9-CM codes, 531.x-534.x), renal diseases (ICD-9-CM codes, 403.01, 403.11, 403.91, 404.02, 404.03, 404.12, 404.13, 404.92, 404.93, 582.x, 583.0-583.7, 585.x, 586.x, V42.0, V45.1, V56.x), liver diseases (ICD-9-CM codes, 070.22, 070.23, 070.32, 070.33, 070.44, 070.54, 070.6, 070.9, 570.x, 571.x, 573.3, 573.4, 573.8, 573.9, V42.7), psychoses (ICD9-CM codes, 293.8, 295.x, 296.04, 296.14, 296.44, 296.54, 297.x, 298.x), and depression (ICD-9-CM codes, 296.2, 296.3, 296.5, 300.4, 309.x, 311.xx).

Cancer diagnoses included cancer [according to the International Classification of Diseases for Oncology (ICD-O-3), oral cavity, 140-146, 148-149; major salivary glands, 142; nasopharyngeal, 147; esophagus, 150; stomach, 151; small intestine, 152; colon, rectum and anus, 153-154; liver and intrahepatic bile ducts, 155; gallbladder and extrahepatic bile ducts, 156; pancreas, 157; posterior peritoneal cavity and peritoneum, 158; unknown site of other digestive organs, 159 nasal, middle ear and paranasal sinuses, 160; larynx, 161; lung, bronchi and trachea, 162; thymus, heart and mediastinum, 163; bone, joint and articular cartilage, 170; connective tissue, subcutaneous tissue and other soft tissue, 171; Skin, 173; female breast, 174; uterus, 179; cervical, 180; uterus, 182; ovary, fallopian tube and broad ligament, 183; other female reproductive organs, 184; prostate; 185; testis, 186; Other male reproductive organs, 187; bladder, 188; kidney, renal pelvis and other urinary system structures, 189; eye and lacrimal gland, 190; brain, 191; other nervous system, 192; thyroid, 193; other endocrine glands, 194; leukemia, 196], initial diagnosis date, cancer type (tissue type and shape), cancer severity (differentiation stage and clinical tumor size), and treatment method (surgery, radiation therapy, and chemotherapy).

Primary outcome. The main outcome of this study was RTW after an initial diagnosis of cancer. Full RTW was defined as the time in calendar days of sick leave until complete work resumption ${ }^{13}$. RTW was confirmed based on employment data from the Labor Insurance database. Unemployment was defined as the employee withdrawing from insurance and not being insured again for 5 years after the initial diagnosis of cancer. The secondary endpoint was the all-cause mortality after RTW within the follow-up period for workers with cancer.

Statistical analysis. The SAS statistical software package (version 9.3, SAS Institute Inc., Cary, North Carolina) was used to analyze the descriptive statistics. Continuous variables are expressed as the mean and standard deviation, and categorical variables are expressed as frequencies and percentages. The independent samples t-test, chi-square test, Pearson product difference correlation, ANOVA and logistic regression were used for inferential statistics analyses. Univariate and multivariate adjustments for the Cox proportional hazard model were used to determine the risk factors that can significantly predict the presence or absence of returning to work. The fully adjusted model includes age, treatment, income range, industrial classification, company size, and cancer stage. The hazard ratio (HR) and 95\% confidence interval (CI) of the HR are provided to indicate the degree of risk. Finally, the survival rates of survivors with different cancer stages were evaluated using KaplanMeier survival analysis. In this study, the statistical significance level $\alpha$ was defined as 0.05 . A $p$-value lower than the significance level indicated statistical significance.

Ethical approval. All procedures performed in studies involving human participants were in accordance with the ethical standards of the institutional and/or national research committee and with the 1964 Helsinki declaration and its later amendments or comparable ethical standards.

Informed consent. Informed consent was obtained from all individual participants included in the study.

\section{Results}

Table 1 provides a summary of returning to work at the fifth year for patients from a fixed cohort with an initial diagnosis of cancer. The average age reemployed patients was $47.6 \pm 9.4$ years old, and the majority were women $(66.7 \%)$. The average age of those who did not return to work was $52.1 \pm 9.7$ years old, and male patients accounted for the majority (60.1\%). In terms of personal disease factors, participants who returned to work had fewer comorbidities than those who did not return to work. In terms of disease treatment, the largest proportion of workers received operation (returning to work: 76.5\%; non-returning to work: $47.7 \%$ ) after cancer diagnosis. In terms of pathological grades, the majority of cancer survivors who returned to work had stage 2-4 disease. Female breast cancer accounted for the highest proportion (24.1\%) of cancer survivors, followed by cervical $(15.9 \%)$ and colorectal and anal (10.1\%) cancer survivors.

In Supplementary Fig. 1, the OR of RTW rapidly increased after the 2nd year in all cancer survivors. A rapid decline was noted after the 4 th year. This implied that cancer survivors might return to work within the first 2-6 years after diagnosis with cancer.

Table 2 shows the number of deaths, survivors, employed individuals, and the number of people who left the workplace in the 1 st to 5 th years after the initial diagnosis of cancer and the 10 most common cancers. A total of $70.4 \%$ of cancer survivors remained employed through the first year after the initial diagnosis of cancer, accounting for $83.4 \%$ of the cancer survivors. After the fifth year, $51.1 \%$ of the cancer survivors remained employed, accounting for $78.7 \%$ of the cancer survivors. In the 1 st year after the initial diagnosis of cancer, patients with cervical cancer $(86.1 \%)$, female breast cancer $(83.6 \%)$ and thyroid cancer $(82.6 \%)$ represented the highest proportion of cancer survivors who remained employed; in the 5th year, patients with cervical cancer $(80.6 \%)$, thyroid cancer $(79.0 \%)$, and female breast cancer $(72.0 \%)$ represented the highest proportion among those who remained employed.

Figures 1 and 2 show the results of the univariate analysis of factors that affect returning to work in the 2 nd and 5 th years after the initial diagnosis. The results showed that age (older) and gender (male) were negatively 


\begin{tabular}{|c|c|c|c|}
\hline \multirow[b]{2}{*}{ Variable } & ALL & RTW & nonRTW \\
\hline & 136,342 & $69,619(51.1 \%)$ & $66,723\left(48.9^{\wedge}\right)$ \\
\hline Age (year) mean $\pm S D$ & $49.8 \pm 9.8$ & $47.6 \pm 9.4$ & $52.1 \pm 9.7$ \\
\hline Gender & 63,247 & $23,169(33.3 \%)$ & $40,078(60.1 \%)$ \\
\hline \multicolumn{4}{|l|}{ Comorbidity } \\
\hline Disorders of lipoid metabolism & 11,997 & $5706(8.2 \%)$ & $6291(9.4 \%)$ \\
\hline Obesity & 353 & $200(0.3 \%)$ & $153(0.2 \%)$ \\
\hline Alcohol abuse & 2466 & $493(0.7 \%)$ & $1973(2.9 \%)$ \\
\hline Hypertension & 24,741 & $10,566(15.2 \%)$ & $14,175(21.2 \%)$ \\
\hline Myocardial infarction & 364 & $125(0.2 \%)$ & $239(0.3 \%)$ \\
\hline Congestive heart failure & 1959 & $623(0.9 \%)$ & $1336(2.0 \%)$ \\
\hline Peripheral vascular disease & 1070 & $440(0.6 \%)$ & $630(0.9 \%)$ \\
\hline Cerebrovascular disease & 3261 & $1037(1.5 \%)$ & $2224(3.3 \%)$ \\
\hline Dementia & 194 & $38(0.1 \%)$ & $156(0.2 \%)$ \\
\hline Chronic pulmonary disease & 7276 & $2605(3.7 \%)$ & $4671(7.0 \%)$ \\
\hline Rheumatologic disease & 1394 & $746(1.1 \%)$ & $648(1.0 \%)$ \\
\hline Peptic ulcer disease & 15,514 & $5997(8.6 \%)$ & $9517(14.3 \%)$ \\
\hline Mild liver disease & 19,189 & $6919(10.0 \%)$ & $12,270(18.4 \%)$ \\
\hline Hemiplegia or paraplegia & 327 & $100(0.1 \%)$ & $227(0.3 \%)$ \\
\hline Renal disease & 3117 & $1133(1.6 \%)$ & $1984(2.9 \%)$ \\
\hline Moderate or severe liver disease & 1600 & $262(0.4 \%)$ & $1338(2.0 \%)$ \\
\hline Psychoses & 667 & $253(0.4 \%)$ & $414(0.6 \%)$ \\
\hline Depression & 3307 & $1597(2.3 \%)$ & $1710(2.6 \%)$ \\
\hline \multicolumn{4}{|l|}{ Treatment } \\
\hline Operation & 65,154 & $40,750(76.5 \%)$ & $24,404(47.7 \%)$ \\
\hline Radiotherapy & 24,378 & $11,989(22.6 \%)$ & $12,389(24.2 \%)$ \\
\hline Chemotherapy & 31,896 & $13,014(24.6 \%)$ & $18,882(36.9 \%)$ \\
\hline Hormone therapy & 10,797 & $7333(13.8 \%)$ & $3464(6.8 \%)$ \\
\hline \multicolumn{4}{|l|}{ Working district } \\
\hline Central & 27,919 & $14,316(20.6 \%)$ & $13,603(20.4 \%)$ \\
\hline North & 67,119 & $34,784(50.0 \%)$ & $32,335(48.4 \%)$ \\
\hline East & 2788 & $1279(1.8 \%)$ & $1509(2.3 \%)$ \\
\hline South & 38,222 & $19,085(27.4 \%)$ & $19,137(28.7 \%)$ \\
\hline Islands & 294 & $155(0.2 \%)$ & $139(0.2 \%)$ \\
\hline \multicolumn{4}{|l|}{ Income range } \\
\hline$\leq 28,800$ & 84,430 & $46,600(66.9 \%)$ & $37,830(56.7 \%)$ \\
\hline$>28,000-38,200$ & 21,308 & $11,703(16.8 \%)$ & $9605(14.4 \%)$ \\
\hline$>38,200$ & 30,604 & $11,316(16.3 \%)$ & $19,288(28.9 \%)$ \\
\hline \multicolumn{4}{|l|}{ Industrial classification } \\
\hline Agriculture, Forestry, Fishing and Husbandry & 9566 & $4760(6.8 \%)$ & $4806(7.2 \%)$ \\
\hline Mining and Quarrying & 98 & $37(0.1 \%)$ & $61(0.1 \%)$ \\
\hline Manufacturing & 42,511 & $21,936(31.5 \%)$ & $20,575(30.8 \%)$ \\
\hline Electricity and Gas Supply & 451 & $146(0.2 \%)$ & $305(0.4 \%)$ \\
\hline Water Supply and Remediation Activities & 891 & $349(0.5 \%)$ & $542(0.8 \%)$ \\
\hline Construction & 15,464 & $6972(10.0 \%)$ & $8492(12.7 \%)$ \\
\hline Wholesale and Retail Trade & 16,656 & $8677(12.4 \%)$ & $7979(11.9 \%)$ \\
\hline Transportation and Storage & 9362 & $4203(6.0 \%)$ & $5159(7.7 \%)$ \\
\hline Accommodation and Food Service Activities & 5527 & $2965(4.2 \%)$ & $2562(3.8 \%)$ \\
\hline Information and Communication & 2033 & $1050(1.5 \%)$ & $983(1.5 \%)$ \\
\hline Financial and Insurance Activities & 3991 & $2299(3.3 \%)$ & $1692(2.5 \%)$ \\
\hline Real Estate Activities & 1561 & $766(1.1 \%)$ & $795(1.2 \%)$ \\
\hline Professional, Scientific and Technical Activities & 3275 & $1715(2.5 \%)$ & $1560(2.3 \%)$ \\
\hline Support Service Activities & 3666 & $1825(2.6 \%)$ & $1841(2.7 \%)$ \\
\hline Public Administration and Defense & 2730 & $1337(1.9 \%)$ & $1393(2.1 \%)$ \\
\hline Education & 2116 & $1254(1.8 \%)$ & $862(1.3 \%)$ \\
\hline Human Health and Social Work Activities & 3215 & $1941(2.8 \%)$ & $1274(1.9 \%)$ \\
\hline Amusement and Recreation Activities & 1567 & $852(1.2 \%)$ & $715(1.1 \%)$ \\
\hline
\end{tabular}




\begin{tabular}{|c|c|c|c|}
\hline \multirow[b]{2}{*}{ Variable } & ALL & RTW & nonRTW \\
\hline & 136,342 & $69,619(51.1 \%)$ & $66,723\left(48.9^{\wedge}\right)$ \\
\hline Other Service Activities & 11,662 & $6535(9.4 \%)$ & $5127(7.7 \%)$ \\
\hline \multicolumn{4}{|l|}{ Company size } \\
\hline Shut down & 13,272 & $6300(9.0 \%)$ & $6972(10.4 \%)$ \\
\hline Small & 9994 & $5096(8.1 \%)$ & $4898(8.2 \%)$ \\
\hline Small and medium & 30,095 & $15,470(24.4 \%)$ & $14,625(24.5 \%)$ \\
\hline Large & 82,981 & $42,753(67.5 \%)$ & $40,228(67.3 \%)$ \\
\hline \multicolumn{4}{|l|}{ Pathological stage } \\
\hline 0 & 9165 & $7505(24.4 \%)$ & $1660(9.2 \%)$ \\
\hline 1 & 14,586 & $10,307(33.5 \%)$ & $4279(23.8 \%)$ \\
\hline 2 & 11,418 & $7588(24.7 \%)$ & $3830(21.3 \%)$ \\
\hline 3 & 8372 & $4101(13.3 \%)$ & $4271(23.7 \%)$ \\
\hline 4 & 5209 & $1261(4.1 \%)$ & $3948(22.0 \%)$ \\
\hline \multicolumn{4}{|l|}{ Cancer type } \\
\hline Oral cavity & 12,222 & $5715(8.2 \%)$ & $6507(9.7 \%)$ \\
\hline Major salivary glands & 485 & $333(0.5 \%)$ & $152(0.2 \%)$ \\
\hline Nasopharyngeal & 4116 & $2388(3.4 \%)$ & $1728(2.6 \%)$ \\
\hline Esophagus & 2989 & $377(0.5 \%)$ & $2612(3.9 \%)$ \\
\hline Stomach & 4467 & $1530(2.2 \%)$ & $2937(4.4 \%)$ \\
\hline Small intestine & 463 & $222(0.3 \%)$ & $241(0.4 \%)$ \\
\hline Colon & 8118 & $3889(5.6 \%)$ & $4229(6.3 \%)$ \\
\hline Rectum and anus & 6348 & $3147(4.5 \%)$ & $3201(4.8 \%)$ \\
\hline Liver and intrahepatic bile ducts & 16,091 & $3733(5.4 \%)$ & $12,358(18.5 \%)$ \\
\hline Gallbladder and extrahepatic bile ducts & 743 & $190(0.3 \%)$ & $553(0.8 \%)$ \\
\hline Pancreas & 1579 & $132(0.2 \%)$ & $1447(2.2 \%)$ \\
\hline Posterior peritoneal cavity and peritoneum & 252 & $105(0.2 \%)$ & $147(0.2 \%)$ \\
\hline Nasal, middle ear and paranasal sinuses & 366 & $181(0.3 \%)$ & $185(0.3 \%)$ \\
\hline Larynx & 820 & $417(0.6 \%)$ & $403(0.6 \%)$ \\
\hline Lung, bronchi and trachea $r$ & 9432 & $1525(2.2 \%)$ & $7907(11.8 \%)$ \\
\hline Thymus, heart and mediastinum & 664 & $310(0.4 \%)$ & $354(0.5 \%)$ \\
\hline Bone, joint and articular cartilage & 274 & $151(0.2 \%)$ & $123(0.2 \%)$ \\
\hline Connective tissue and other soft tissue & 830 & $440(0.6 \%)$ & $390(0.6 \%)$ \\
\hline Skin & 2935 & $2018(2.9 \%)$ & $917(1.4 \%)$ \\
\hline Female breast & 23,292 & $16,768(24.1 \%)$ & $6524(9.8 \%)$ \\
\hline Cervix & 13,708 & $11,048(15.9 \%)$ & $2660(4.0 \%)$ \\
\hline Uterus & 3174 & $2282(3.3 \%)$ & $892(1.3 \%)$ \\
\hline Ovary, fallopian tube and broad ligament & 2489 & $1380(1.9 \%)$ & $1109(1.7 \%)$ \\
\hline Prostate & 1647 & $802(1.1 \%)$ & $845(1.3 \%)$ \\
\hline Testis & 398 & $308(0.4 \%)$ & $90(0.1 \%)$ \\
\hline Bladder cancer & 2528 & $1476(2.1 \%)$ & $1052(1.6 \%)$ \\
\hline Kidney & 1532 & $857(1.2 \%)$ & $675(1.0 \%)$ \\
\hline Renal pelvis and other urinary structures & 1245 & $607(0.9 \%)$ & $638(0.9 \%)$ \\
\hline Eye and lacrimal gland & 144 & $90(0.1 \%)$ & $54(0.1 \%)$ \\
\hline Brain & 1169 & $364(0.5 \%)$ & $805(1.2 \%)$ \\
\hline Thyroid & 5439 & $4295(6.2 \%)$ & $1144(1.7 \%)$ \\
\hline Leukemia & 4618 & $1977(2.8 \%)$ & $2641(3.9 \%)$ \\
\hline Others & 605 & $337(0.5 \%)$ & $268(0.4 \%)$ \\
\hline
\end{tabular}

Table 1. Demographic data of RTW group and non-RTW group in the 5th year.

associated with returning to work. Alcohol abuse, hypertension, myocardial infarction, heart failure, peripheral arterial disease, cerebrovascular disease, dementia, chronic pulmonary diseases, peptic ulcer, mild liver disease, hemiparesis, kidney disease, moderate-severe liver diseases and mental illness were significantly negatively associated with RTW in the 2nd and 5th years, and dyslipidemia and depression were significantly negatively associated with returning to work only in the fifth year. Surgical treatment showed a significant positive relationship with RTW in the 2nd and 5th years. Radiation therapy and chemotherapy were significantly negatively associated with returning to work in the 2 nd and 5th year. Based on histopathological staging, compared to the highest 


\begin{tabular}{|c|c|c|c|c|c|c|}
\hline \multirow[b]{2}{*}{ Cancer type } & \multirow[b]{2}{*}{ Work status } & \multicolumn{5}{|l|}{ Time } \\
\hline & & 1 st year & 2nd year & 3rd year & 4th year & 5th year \\
\hline \multirow{6}{*}{ All cancers $(\mathrm{N}=136,342)$} & Death & 21,616 & 32,974 & 39,764 & 44,389 & 47,851 \\
\hline & Change work & 89,658 & 75,076 & 66,917 & 61,695 & 58,125 \\
\hline & RTW & 6312 & 9238 & 10,472 & 11,075 & 11,494 \\
\hline & Unemployment & 18,756 & 19,054 & 19,189 & 19,183 & 18,872 \\
\hline & Survival rate (\%) & 84.15 & 75.82 & 70.84 & 67.44 & 64.90 \\
\hline & Employment rate (\%) & 70.39 & 61.84 & 56.76 & 53.37 & 51.06 \\
\hline \multirow{6}{*}{ Breast $(\mathrm{N}=23,292)$} & Death & 353 & 923 & 1552 & 2114 & 2621 \\
\hline & Change work & 18,193 & 16,652 & 15,509 & 14,700 & 14,107 \\
\hline & RTW & 1279 & 2024 & 2394 & 2548 & 2661 \\
\hline & Unemployment & 3467 & 3693 & 3837 & 3930 & 3903 \\
\hline & Survival rate (\%) & 98.5 & 96.0 & 93.3 & 90.9 & 88.7 \\
\hline & Employment rate (\%) & 83.6 & 80.2 & 76.9 & 74.1 & 72.0 \\
\hline \multirow{6}{*}{ Liver and intrahepatic bile ducts $(\mathrm{N}=16,091)$} & Death & 6535 & 8479 & 9675 & 10,488 & 11,080 \\
\hline & Change work & 7573 & 5605 & 4498 & 3778 & 3281 \\
\hline & RTW & 414 & 477 & 462 & 456 & 452 \\
\hline & Unemployment & 1569 & 1530 & 1456 & 1369 & 1278 \\
\hline & Survival rate (\%) & 59.4 & 47.3 & 39.9 & 34.8 & 31.1 \\
\hline & Employment rate (\%) & 49.6 & 37.8 & 30.8 & 26.3 & 23.2 \\
\hline \multirow{6}{*}{ Cervix $(\mathrm{N}=13,708)$} & Death & 212 & 470 & 674 & 814 & 895 \\
\hline & Change work & 10,866 & 10,044 & 9563 & 9274 & 9091 \\
\hline & RTW & 940 & 1435 & 1701 & 1842 & 1957 \\
\hline & Unemployment & 1690 & 1759 & 1770 & 1778 & 1765 \\
\hline & Survival rate (\%) & 98.5 & 96.6 & 95.1 & 94.1 & 93.5 \\
\hline & Employment rate (\%) & 86.1 & 83.7 & 82.2 & 81.1 & 80.6 \\
\hline \multirow{6}{*}{ Oral cavity $(\mathrm{N}=12,222)$} & Death & 1880 & 3435 & 4101 & 4596 & 4992 \\
\hline & Change work & 8253 & 6541 & 5776 & 5231 & 4844 \\
\hline & RTW & 540 & 749 & 820 & 851 & 871 \\
\hline & Unemployment & 1549 & 1497 & 1525 & 1544 & 1515 \\
\hline & Survival rate (\%) & 84.6 & 71.9 & 66.4 & 62.4 & 59.2 \\
\hline & Employment rate (\%) & 71.9 & 59.6 & 54.0 & 49.8 & 46.8 \\
\hline \multirow{6}{*}{ Trachea, bronchus, and lung $(\mathrm{N}=9432)$} & Death & 3353 & 5181 & 6285 & 6871 & 7219 \\
\hline & Change work & 4719 & 2960 & 2027 & 1555 & 1295 \\
\hline & RTW & 246 & 292 & 265 & 238 & 230 \\
\hline & Unemployment & 1114 & 999 & 855 & 768 & 688 \\
\hline & Survival rate (\%) & 64.5 & 45.1 & 33.4 & 27.2 & 23.5 \\
\hline & Employment rate (\%) & 52.6 & 34.5 & 24.3 & 19.0 & 16.2 \\
\hline \multirow{6}{*}{ Colon $(\mathrm{N}=8118)$} & Death & 941 & 1673 & 2182 & 2508 & 2754 \\
\hline & Change work & 5548 & 4551 & 3944 & 3571 & 3315 \\
\hline & RTW & 319 & 472 & 521 & 546 & 574 \\
\hline & Unemployment & 1310 & 1422 & 1471 & 1493 & 1475 \\
\hline & Survival rate (\%) & 88.4 & 79.4 & 73.1 & 69.1 & 66.1 \\
\hline & Employment rate (\%) & 72.3 & 61.9 & 55.0 & 50.7 & 47.9 \\
\hline \multirow{6}{*}{ Rectum and anus $(\mathrm{N}=6348)$} & Death & 480 & 1011 & 1432 & 1740 & 1977 \\
\hline & \begin{tabular}{|l|} 
Change work \\
\end{tabular} & 4516 & 3744 & 3264 & 2917 & 2692 \\
\hline & RTW & 266 & 413 & 442 & 451 & 455 \\
\hline & Unemployment & 1086 & 1180 & 1210 & 1240 & 1224 \\
\hline & Survival rate (\%) & 92.4 & 84.1 & 77.4 & 72.6 & 68.9 \\
\hline & Employment rate (\%) & 75.3 & 65.5 & 58.4 & 53.1 & 49.6 \\
\hline \multirow{6}{*}{ Thyroid gland $(\mathrm{N}=5439)$} & Death & 68 & 94 & 113 & 130 & 153 \\
\hline & \begin{tabular}{|l|} 
Change work \\
\end{tabular} & 4086 & 3816 & 3647 & 3539 & 3446 \\
\hline & RTW & 405 & 599 & \begin{tabular}{|l|l|}
719 \\
\end{tabular} & 800 & 849 \\
\hline & Unemployment & 880 & 930 & 960 & 970 & 991 \\
\hline & Survival rate (\%) & 98.7 & 98.3 & 97.9 & 97.6 & 97.2 \\
\hline & Employment rate (\%) & 82.6 & 81.2 & 80.3 & 79.8 & 79.0 \\
\hline Continued & & & & & & \\
\hline
\end{tabular}




\begin{tabular}{|c|c|c|c|c|c|c|}
\hline \multirow[b]{2}{*}{ Cancer type } & \multirow[b]{2}{*}{ Work status } & \multicolumn{5}{|l|}{ Time } \\
\hline & & 1 st year & 2nd year & 3rd year & 4th year & 5th year \\
\hline \multirow{6}{*}{ Leukemia $(\mathrm{N}=4618)$} & Death & 1057 & 1543 & 1761 & 1904 & 2013 \\
\hline & Change work & 2638 & 2059 & 1815 & 1654 & 1545 \\
\hline & RTW & 212 & 330 & 380 & 420 & 432 \\
\hline & Unemployment & 711 & 686 & 662 & 640 & 628 \\
\hline & Survival rate (\%) & 77.1 & 66.6 & 61.9 & 58.8 & 56.4 \\
\hline & Employment rate (\%) & 61.7 & 51.7 & 47.5 & 44.9 & 42.8 \\
\hline \multirow{6}{*}{ Stomach $(\mathrm{N}=4467)$} & Death & 1253 & 1850 & 2136 & 2296 & 2404 \\
\hline & Change work & 2489 & 1857 & 1567 & 1393 & 1289 \\
\hline & RTW & 154 & 206 & 227 & 236 & 241 \\
\hline & Unemployment & 571 & 554 & 537 & 542 & 533 \\
\hline & Survival rate (\%) & 71.9 & 58.6 & 52.2 & 48.6 & 46.2 \\
\hline & Employment rate (\%) & 59.2 & 46.2 & 40.2 & 36.5 & 34.3 \\
\hline
\end{tabular}

Table 2. Longitudinal distribution of workers with cancer in 5 years (2004-2010).
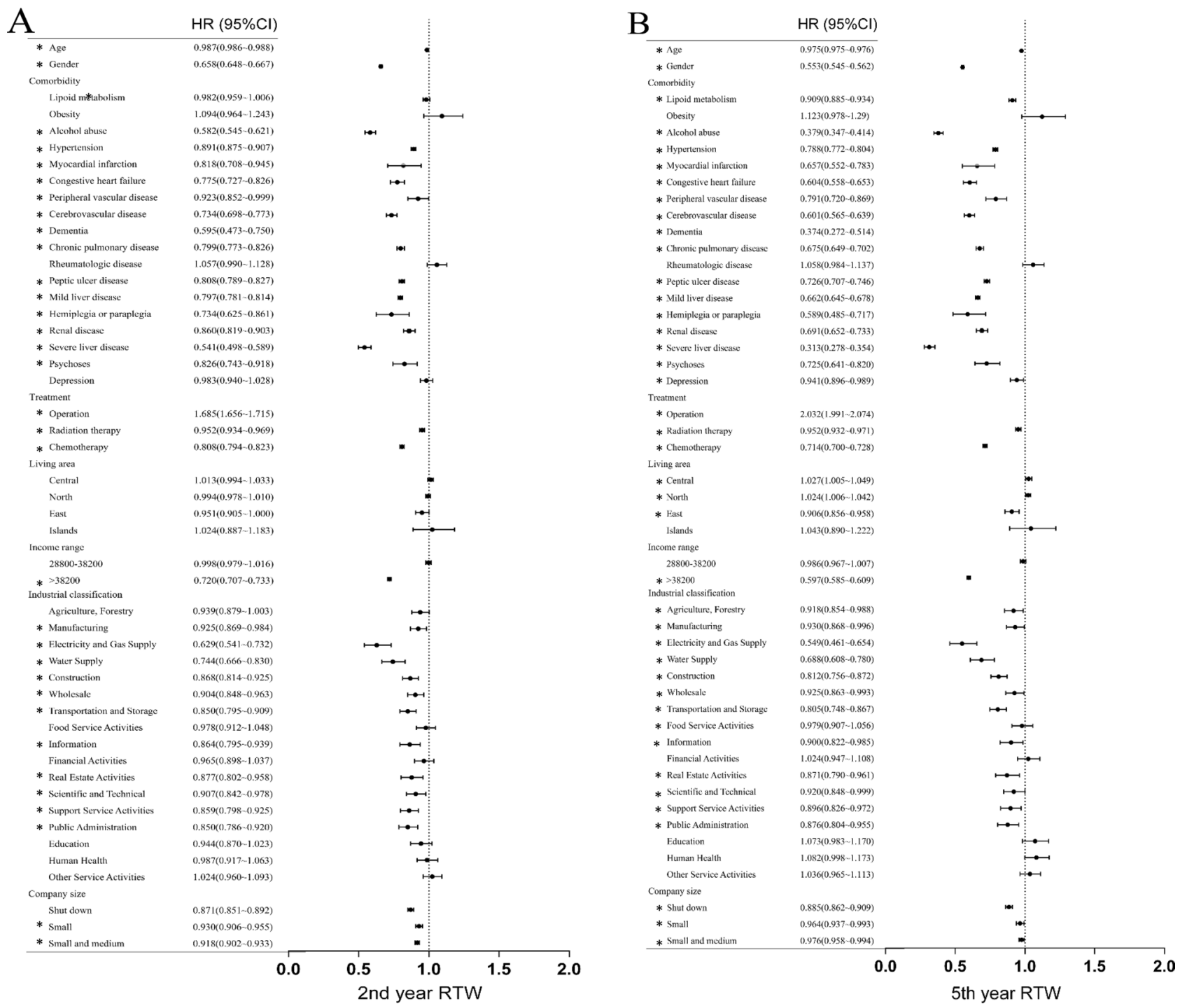

Figure 1. Univariate association between independent variables and RTW in the 2nd and 5th year. 

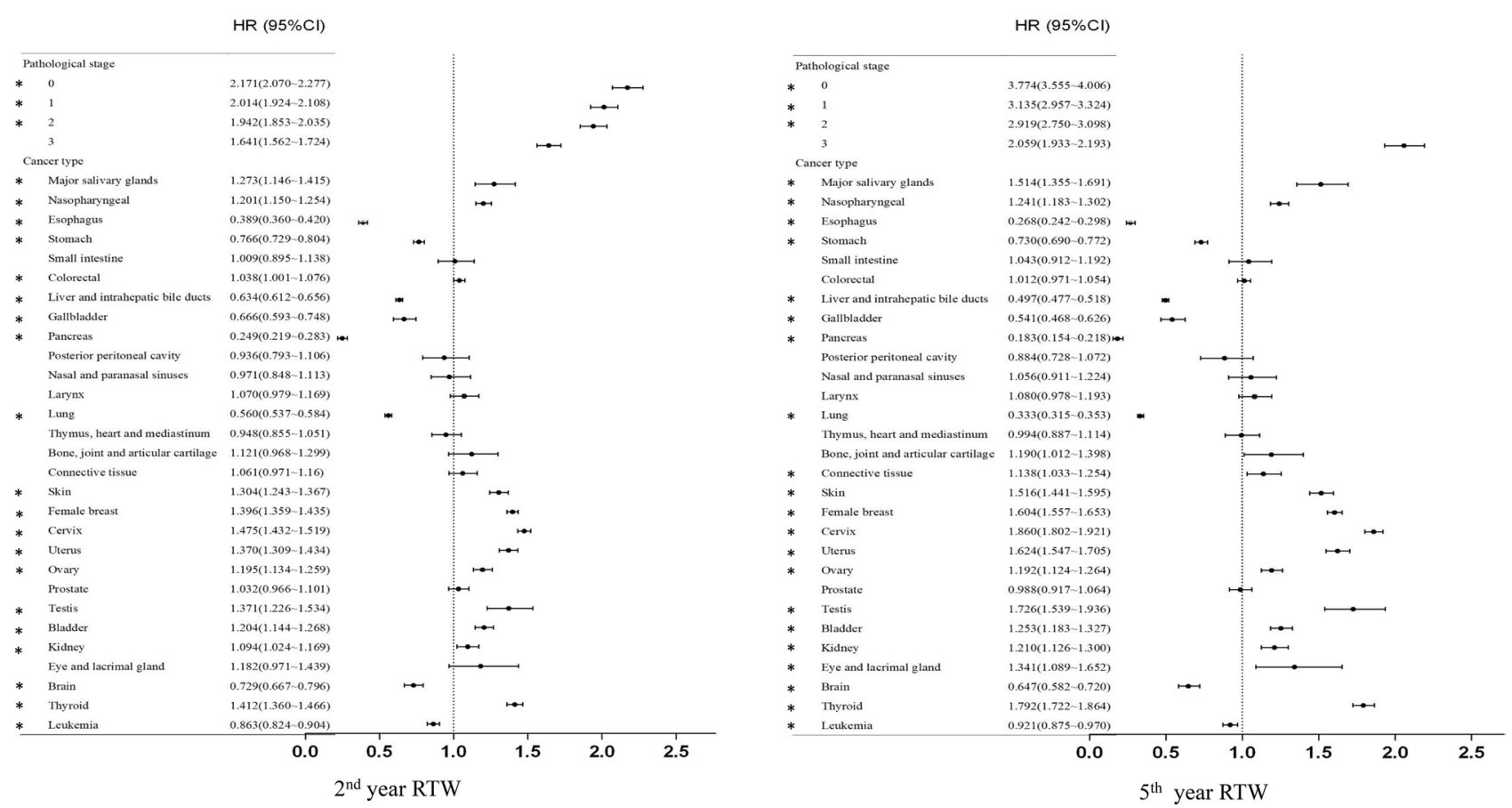

Figure 2. Univariate association between different cancer types and RTW in the 2nd and 5th year.

stage (stage 4), lower stages were significantly positively associated with returning to work in the 2 nd and 5 th year. In terms of cancer types, we used oral cancer, which is prevalent in Taiwan and Southeast Asia, as the reference. The results showed that patients with salivary gland cancer, nasopharyngeal carcinoma, osteocarcinoma, chondrocarcinoma, sarcoma, skin cancer, female breast cancer, female genital cancer, testicular cancer, bladder cancer, renal cancer and thyroid cancer were significantly associated with increased rates of returning to work in the 5th years. In contrast, esophageal cancer, gastric cancer, hepatic cancer and intrahepatic cholangiocarcinoma, gallbladder cancer and extrahepatic cholangiocarcinoma, pancreatic cancer, thoracic cancer, brain cancer, and leukemia were significantly associated with reduced returning to work in the 5th year.

Figure 3 presents the relationship between the different variables and the occurrence of returning to work in the 2 nd and 5 th years. The results showed that the HR of returning to work in the 2 nd and 5 th years was decreased for patients with the following characteristics: older age, male sex, difference in salary level greater than 38,200 New Taiwan Dollars, receiving chemotherapy, working in medium/small scale industry, and advanced cancer stage. In contrast, for patients who underwent surgery or radiotherapy, the HR of returning to work in the 2 nd and 5 th years was still increased. The most notable change was for radiation therapy. In the univariate analysis, radiation therapy was a negative factor for returning to work, but it was a positive factor in the multivariate analysis.

Figure 4 displays the survival rates of survivors with different cancer stages (A: all stages; B: stage 0; C: stage 1; D: stage 2; E: stage 3; F: stage 4) evaluated using Kaplan-Meier survival analysis. The survival rates of all cancer stages were significantly higher in the returning to work group than in the non- returning to work group $(p<0.001)$. The returning to work group had significantly higher survival rates than the non- returning to work group for survivors with stage $1,2,3$, and 4 diseases $(p<0.001)$. Table 3 shows the association between returning to work and all-cause mortality. Patents who returned to work had significantly reduced risk of all-cause mortality with an HR of 0.46 (95\%CI: $0.44-0.48, p<0.001)$ after fully adjusting for the variables.

\section{Discussion}

The aim of this study was to analyze the return to work of cancer survivors in Taiwan by combining Taiwan's Labor Insurance Database, National Health Insurance Research Database and Taiwan Cancer Registry. This study used a retrospective cohort study design to establish a cohort of cancer survivors with an initial diagnosis of cancer from 2004 to 2010 . From the beginning to the end of the observation, there were no newly added research cases, and no study cases remained. This study found that among the patients with an initial diagnosis, $70.4 \%$ of the workers remained employed through the first year, accounting for $83.4 \%$ of the cancer survivors. In the fifth year after the diagnosis, $51.1 \%$ of the patients remained employed, accounting for $78.7 \%$ of cancer survivors, a decrease from the first year. The results of our study showed that the important factors affecting whether patients with an initial diagnosis of cancer returned to work include age, gender, salary level, treatment method, enterprise size and cancer stage and whether returning to work was the key factor affecting the future survival of patients.

The relationship between cancer and returning to work has been presented in numerous studies. Fantoni et al. demonstrated that a high proportion of employed patients with breast cancer returned to work in 36 months after treatment ${ }^{14}$. In a recent study, the risk factors affecting returning to work of cancer survivors included 
A

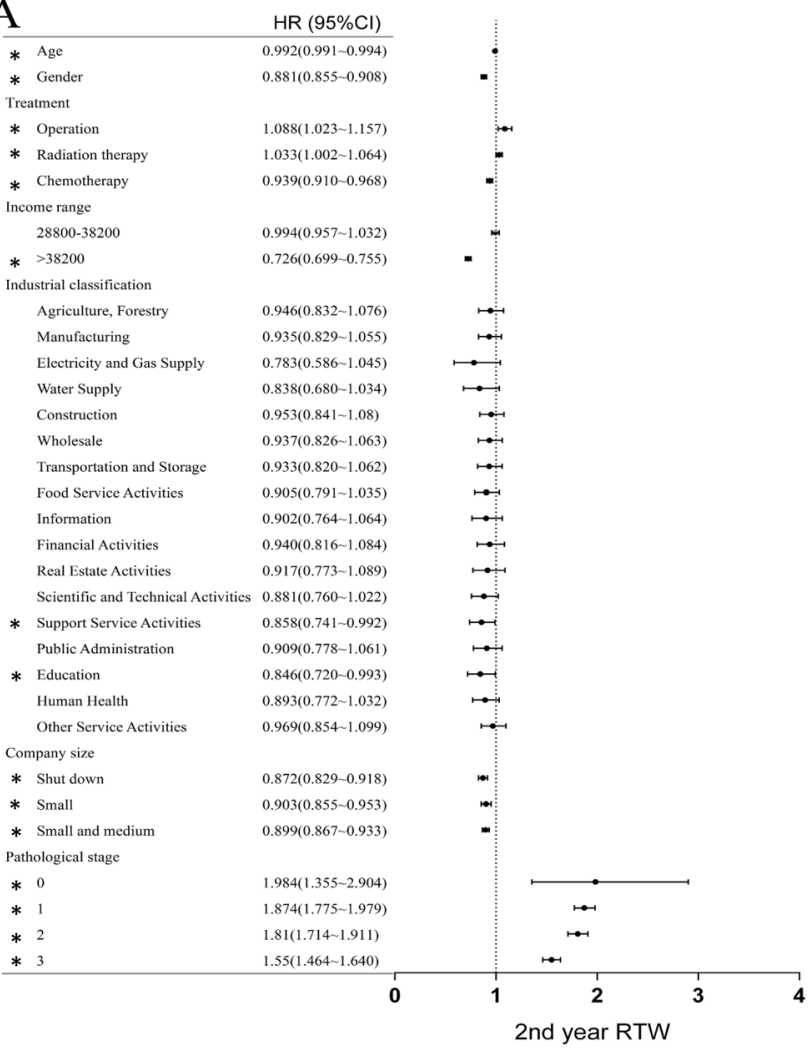

B

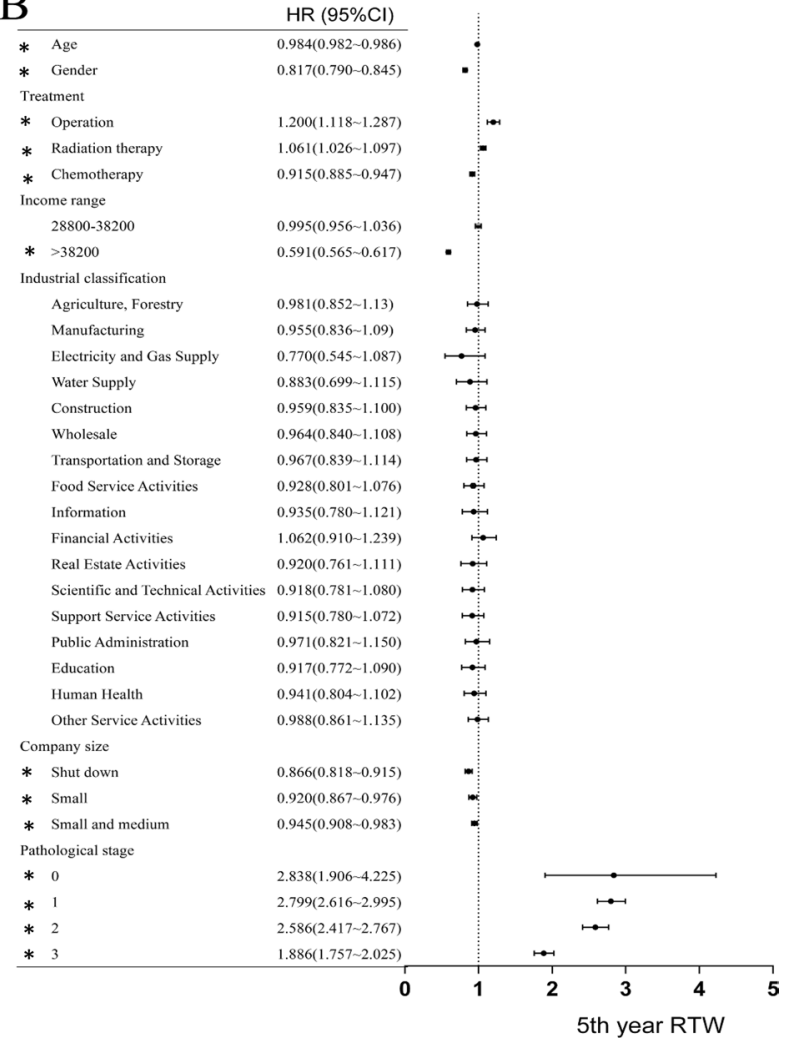

Figure 3. Multivariate association between independent variables and RTW in the 2nd and 5th year.

personal, employment, and socioeconomic factors ${ }^{15}$. Chen et al. demonstrated that RTW may have a beneficial effect on the survival of patients with oral cancer in Taiwan ${ }^{16}$. Among the cancer and symptom factors, in our study, the chances of returning to work were higher for the patients who received surgical treatment. However, if patients received chemotherapy and radiotherapy, the chances of returning to work were relatively low. The reasons for this may be that the patients who received only surgical treatment had their cancer detected at an early stage. Patients with relatively advanced stage disease may require chemotherapy and radiotherapy. In addition, chemotherapy and radiotherapy require 3-6 months, and patients need to visit the hospital or outpatient clinic for several courses of treatment and are more prone to complications or discomfort. Consistent with our findings, a study on breast cancer survivors with a median monthly follow-up of 36 months found that chemotherapy or radiotherapy restricted or postponed returning to work, possibly due to end-stage cancer patients requiring multiple treatment strategies ${ }^{14}$. The multifactor analysis indicated that changes in receiving radiotherapy were a positive factor for returning to work; however, the possible reason for this result was that our study did not group survivors according to multiple treatment strategies. For cancer staging, compared to patients with stage 4 cancer, patients with lower-stage cancer (e.g., stage 1) had a greater chance of returning to work. Studies from other counties also showed that patients with terminal cancer or palliative treatments were associated with a lower return to work rate ${ }^{17,18}$. In terms of cancer types, previous studies have shown that liver cancer, pulmonary cancer, brain cancer, blood cancer, gastrointestinal cancer, pancreatic cancer, head and neck cancer, and gynecological cancer are all significantly correlated with unemployment or losing jobs ${ }^{18-22}$. Another study found that male and female genital cancer, skin cancer and breast cancer had the highest return to work rate 2 years after a cancer diagnosis ${ }^{23}$. Cervical cancer and female breast cancer survivors had a higher return to work rate, possibly due to the continued promotion of Pap smear screening and breast cancer screening by the Taiwan Health Promotion Administration ${ }^{24}$. Women over the age of 30 can receive an annual free Pap smear examination and women aged 45-69 years old or 40-44 years old with a family history of breast cancer in firstor second-degree relatives can receive free mammography once every 2 years. These screening programs can greatly improve the diagnostic rate of early cervical cancer and breast cancer, thereby reducing disability and work-related issues in working women ${ }^{25,26}$.

For demographic factors, based on age, the older an individual is, the lower the chance of the patient returning to work, which may also be related to the retirement age in Taiwan (according to the Ministry of Labor's statistics, Taiwan's actual retirement age from 2010 to 2015 was 63.3 years for men and 60.6 years for women. In this study, the average age of patients in the fifth year after the initial diagnosis was 49.8 years old, the average age of patients who returned to work was 47.6 years old, and the average age of patients who did not return to work was 52.1 years old). Because the age at diagnosis was close to the retirement age, patient motivation to return to work may be decreased. In a Danish study, compared with younger patients, older patients (50-60 years) had a higher unemployment rate ${ }^{27}$. In addition, studies have shown that demographic factors that affect return to work included gender and low socioeconomic levels ${ }^{18}$. Marino's study addressing gender and return to work showed 

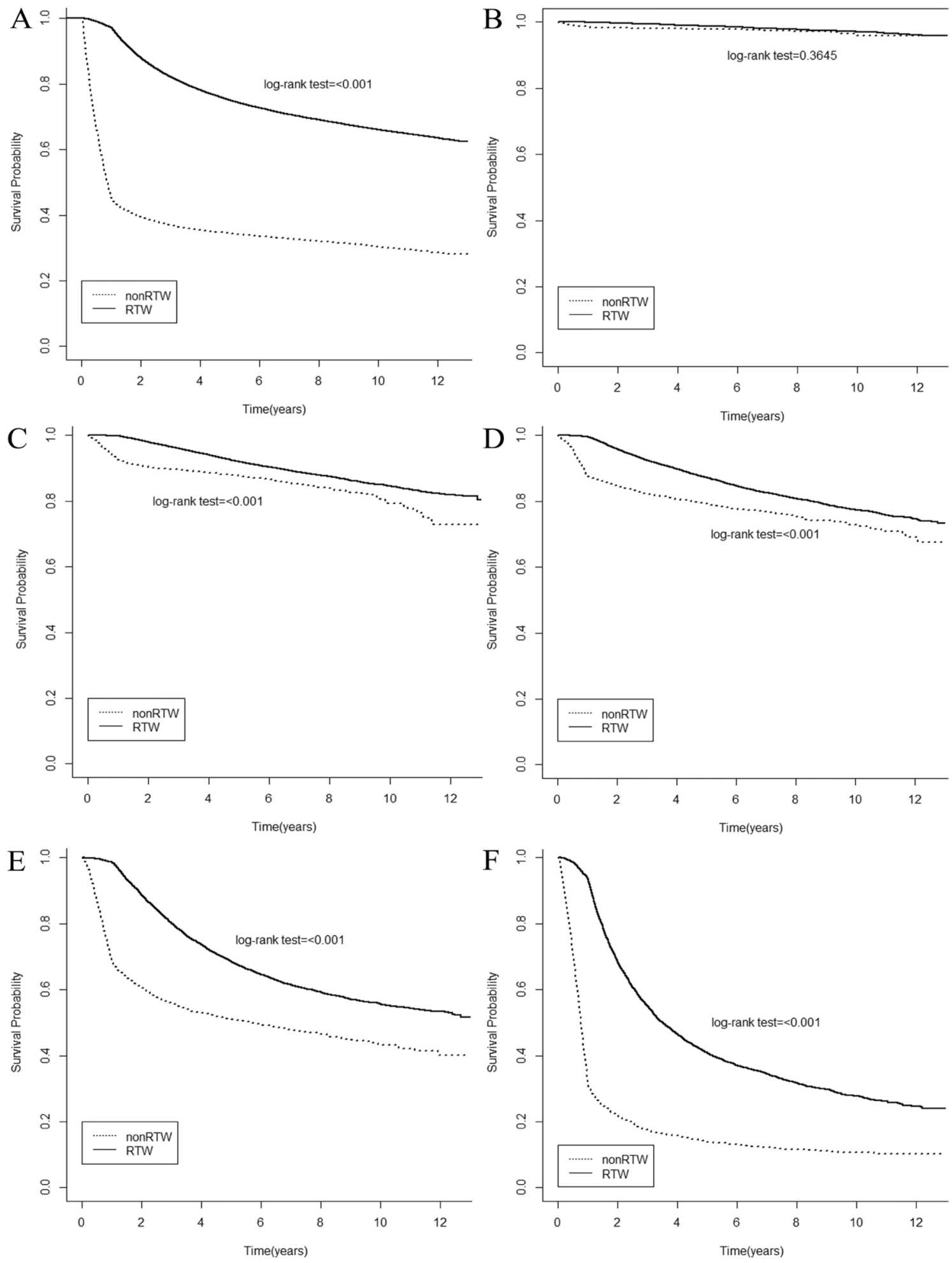

Figure 4. Kaplan-Meier curve for all-cause mortality categorized by all cancer stages. (A) all stages (B) stage 0; (C) stage 1 ; (D) stage 2; (E) stage 3; (F) stage 4.

\begin{tabular}{|l|l|l|l|c|}
\hline & Unadjusted HR $(\mathbf{9 5} \%$ CI $)$ & $\boldsymbol{p}$ value & Fully adjusted HR $(\mathbf{9 5 \%}$ CI) & $\boldsymbol{p}$ value \\
\hline RTW & $0.25(0.25-0.26)$ & $<0.001$ & $0.46(0.44-0.48)$ & $<0.001$ \\
\hline
\end{tabular}

Table 3. Associations between returning to work and all-cause mortality. Adjusted covariates: age, treatment, income range, industrial classification, company size, cancer stage, return to work. 
that among patients who were still alive 2 years after a cancer diagnosis, older men returned to work later than did older women, but married men returned to work earlier than did married women ${ }^{28}$. In our cohort, women were more likely to return to work than men, probably due to the high proportion of women with cervical cancer and breast cancer, which are mainly identified at early stages. Oral cancer is more common in Taiwanese men and is mostly caused by chewing betel nuts and smoking. In the fifth year, returning to work of men with oral cancer was only half that of women with cervical cancer and breast cancer.

Survival prognosis is an important indicator for cancer survivors. After confirming prognostic factors that affect survival, health education, rehabilitation and treatment are performed to improve the survival and the quality of life of patients. In our study, returning to work significantly affected the prognosis of patients, especially for patients with stage 4 cancer. Daily physical performance, for example, can be measured with the US Eastern Cooperative Oncology Group and Karnofsky performance scales In a study of pancreatic cancer, poor daily physical performance was significantly correlated with a poor prognosis ${ }^{29}$. In patients with breast cancer that metastasized to the brain, physical performance in the presence of metastasis can predict survival ${ }^{30}$. Good physical performance is especially important for patients with advanced stage cancer, indicating that return to work can effectively predict the survival of these patients ${ }^{31}$.

An advantage of this study is the analysis of big data from a labor insurance and health insurance database in Taiwan. At the end of 2016, there were a total of 10,165,434 people were enrolled in labor insurance. The 2 databases were merged, and information related to the diagnoses and treatment of cancer survivors and changes in employment over 11 years were tracked. A limitation of this study is that the database did not include other important factors for determining the return to work of cancer survivors, such as education level, family support, personal physical performance status, work effort level, etc. As a result, there are limitations related to the inferences that can be made.

In this study, important factors for returning to work RTW included chronic diseases, gender, age, salary, and cancer stage. In particular, we also found that returning to work was significantly associated with the survival of the patients. For the country and society, the return to work of patients with cancer can boost the social labor force and promote the national economy. For working-age patients, a cancer diagnosis and subsequent return to work after treatment is an important transition milestone from being a cancer patient to being a cancer survivor. Returning to work indicates recovery. The path to the return to work of cancer survivors requires not only interdisciplinary professional intervention but also the assistance of the state, society, and employers. Strengthening existing returning to work policies and assisting high-risk populations to return to work after treatment should be a priority to protect these individuals' right to work and to maintain the overall labor force.

Received: 23 January 2021; Accepted: 9 June 2021

Published online: 18 June 2021

\section{References}

1. Young, Y. C. \& Chang, K. C. Causes of death in workers from 2003 to 2008. J. Occup. Saf. Health 57, 527-538 (2014).

2. Tamminga, S. J., de Boer, A. G., Verbeek, J. H. \& Frings-Dresen, M. H. Return-to-work interventions integrated into cancer care: A systematic review. Occup. Environ. Med. 67, 639-648. https://doi.org/10.1136/oem.2009.050070 (2010).

3. Stone, D. S., Ganz, P. A., Pavlish, C. \& Robbins, W. A. Young adult cancer survivors and work: A systematic review. J. Cancer Surviv.: Res. Pract. 11, 765-781. https://doi.org/10.1007/s11764-017-0614-3 (2017).

4. Tavan, H., Azadi, A. \& Veisani, Y. Return to work in cancer patients: A systematic review and meta-analysis. Indian J Palliat Care 25, 147-152. https://doi.org/10.4103/IJPC.IJPC_114_18 (2019).

5. Colombino, I. C. F., Sarri, A. J., Castro, I. Q., Paiva, C. E. \& da Vieira, R. A. C. Factors associated with return to work in breast cancer survivors treated at the Public Cancer Hospital in Brazil. Support. Care Cancer 28, 4445-4458. https://doi.org/10.1007/ s00520-019-05164-7 (2020).

6. Smith, T. et al. The rationale, design, and implementation of the American Cancer Society's studies of cancer survivors. Cancer 109, 1-12. https://doi.org/10.1002/cncr.22387 (2007).

7. Bradley, C. J. \& Bednarek, H. L. Employment patterns of long-term cancer survivors. Psychooncology 11, 188-198. https://doi.org/ 10.1002/pon.544 (2002).

8. Gordon, L., Lynch, B. M. \& Newman, B. Transitions in work participation after a diagnosis of colorectal cancer. Aust. N. Z. J. Public Health 32, 569-574. https://doi.org/10.1111/j.1753-6405.2008.00312.x (2008).

9. Ferrell, B. R., Grant, M. M., Funk, B., Otis-Green, S. \& Garcia, N. Quality of life in breast cancer survivors as identified by focus groups. Psychooncology 6, 13-23. https://doi.org/10.1002/(sici)1099-1611(199703)6:1\%3c13::Aid-pon231\%3e3.0.Co;2-s (1997).

10. Jeong, I., Yoon, J.-H., Roh, J., Rhie, J. \& Won, J.-U. Association between the return-to-work hierarchy and self-rated health, selfesteem, and self-efficacy. Int. Arch. Occup. Environ. Health 92, 709-716. https://doi.org/10.1007/s00420-019-01406-7 (2019).

11. Feuerstein, M. et al. Work in cancer survivors: A model for practice and research. J. Cancer Surviv.: Res. Pract. 4, 415-437. https:// doi.org/10.1007/s11764-010-0154-6 (2010).

12. Mehnert, A. Employment and work-related issues in cancer survivors. Crit. Rev. Oncol. Hematol. 77, 109-130. https://doi.org/10. 1016/j.critrevonc.2010.01.004 (2011).

13. Hoefsmit, N. et al. The effectiveness of an intervention to enhance cooperation between sick-listed employees and their supervisors (COSS). J. Occup. Rehabil. 26, 229-236. https://doi.org/10.1007/s10926-015-9606-1 (2016).

14. Fantoni, S. Q. et al. Factors related to return to work by women with breast cancer in northern France. J. Occup. Rehabil. 20, 49-58. https://doi.org/10.1007/s10926-009-9215-y (2010).

15. Butow, P., Laidsaar-Powell, R., Konings, S., Lim, C. Y. S. \& Koczwara, B. Return to work after a cancer diagnosis: A meta-review of reviews and a meta-synthesis of recent qualitative studies. J. Cancer Surviv.: Res. Pract. 14, 114-134. https://doi.org/10.1007/ s11764-019-00828-Z (2020).

16. Chen, Y. Y. et al. Trajectories of returning to work and its impact on survival in survivors with oral cancer: A 5-year follow-up study. Cancer 126, 1225-1234. https://doi.org/10.1002/cncr.32643 (2020).

17. Mehnert, A. \& Koch, U. Predictors of employment among cancer survivors after medical rehabilitation-a prospective study. Scand. J. Work Environ. Health 39, 76-87. https://doi.org/10.5271/sjweh.3291 (2013).

18. Short, P. F., Vasey, J. J. \& Tunceli, K. Employment pathways in a large cohort of adult cancer survivors. Cancer 103, $1292-1301$. https://doi.org/10.1002/cncr.20912 (2005). 
19. de Boer, A. G., Taskila, T., Ojajarvi, A., van Dijk, F. J. \& Verbeek, J. H. Cancer survivors and unemployment: A meta-analysis and meta-regression. JAMA 301, 753-762. https://doi.org/10.1001/jama.2009.187 (2009).

20. Choi, K. S. et al. Job loss and reemployment after a cancer diagnosis in Koreans-a prospective cohort study. Psychooncology 16, 205-213. https://doi.org/10.1002/pon.1054 (2007).

21. Park, J. H., Park, E. C., Park, J. H., Kim, S. G. \& Lee, S. Y. Job loss and re-employment of cancer patients in Korean employees: A nationwide retrospective cohort study. J. Clin. Oncol.: Off. J. Am. Soc. Clin. Oncol. 26, 1302-1309. https://doi.org/10.1200/jco.2007. 14.2984 (2008).

22. Taskila-Brandt, T. et al. The impact of education and occupation on the employment status of cancer survivors. Eur. J. Cancer (Oxford, England: 1990) 40, 2488-2493. https://doi.org/10.1016/j.ejca.2004.06.031 (2004).

23. Roelen, C. A., Koopmans, P. C., Groothoff, J. W., van der Klink, J. J. \& Bultmann, U. Sickness absence and full return to work after cancer: 2-year follow-up of register data for different cancer sites. Psychooncology 20, 1001-1006. https://doi.org/10.1002/pon. 1820 (2011).

24. Wang, P. D. \& Lin, R. S. Sociodemographic factors of Pap smear screening in Taiwan. Public Health 110, 123-127. https://doi.org/ 10.1016/s0033-3506(96)80059-x (1996).

25. Kau, Y.-C. et al. Trend and survival outcome in Taiwan cervical cancer patients: A population-based study. Medicine $\mathbf{9 8}$, e14848. https://doi.org/10.1097/md.0000000000014848 (2019).

26. Wu, T. Y. et al. Understanding breast cancer screening practices in Taiwan: A country with universal health care. Asian Pac. J. Cancer Prev.: APJCP 13, 4289-4294. https://doi.org/10.7314/apjcp.2012.13.9.4289 (2012).

27. Carlsen, K., Dalton, S. O., Diderichsen, F. \& Johansen, C. Risk for unemployment of cancer survivors: A Danish cohort study. Eur. J. Cancer 44, 1866-1874. https://doi.org/10.1016/j.ejca.2008.05.020 (2008).

28. Marino, P., Teyssier, L. S., Malavolti, L. \& Le Corroller-Soriano, A. G. Sex differences in the return-to-work process of cancer survivors 2 years after diagnosis: Results from a large French population-based sample. J. Clin. Oncol. 31, 1277-1284. https://doi. org/10.1200/JCO.2011.38.5401 (2013).

29. Rudra, S. et al. Evaluation of predictive variables in locally advanced pancreatic adenocarcinoma patients receiving definitive chemoradiation. Pract. Radiat. Oncol. 2, 77-85. https://doi.org/10.1016/j.prro.2011.06.009 (2012).

30. Jeon, W. et al. Analysis of survival outcomes based on molecular subtypes in breast cancer brain metastases: A single institutional cohort. Breast J. 24, 920-926. https://doi.org/10.1111/tbj.13111 (2018).

31. Verweij, N. M., Schiphorst, A. H. W., Pronk, A., van den Bos, F. \& Hamaker, M. E. Physical performance measures for predicting outcome in cancer patients: A systematic review. Acta Oncol. 55, 1386-1391. https://doi.org/10.1080/0284186X.2016.1219047 (2016).

\title{
Author contributions
}

C.-C.W. and W.-L.C. contributed to the design of the study, were responsible for the management and retrieval of data, contributed to initial data analysis and interpretation, drafted the initial manuscript. W.-L.C., Y.-Y.C., W.T.W., C.-L.H., and C.-C.W. decided upon the data collection methods and initial data analysis and interpretation. C.-C.W. and W.-L.C. were also responsible for the data analysis decisions. C.-C.W. conceptualized and designed the study, supervised all aspects of the study, critically reviewed and revised the manuscript, and approved the final manuscript as submitted.

\section{Funding}

This study was funded by the Institute of Labor, Occupational Safety, and Health (ILOSH) and the Ministry of Labor (ILOSH107-M301) in Taiwan.

\section{Competing interests}

The authors declare no competing interests.

\section{Additional information}

Supplementary Information The online version contains supplementary material available at https://doi.org/ 10.1038/s41598-021-92306-9.

Correspondence and requests for materials should be addressed to C.-C.W.

Reprints and permissions information is available at www.nature.com/reprints.

Publisher's note Springer Nature remains neutral with regard to jurisdictional claims in published maps and institutional affiliations.

\begin{abstract}
Open Access This article is licensed under a Creative Commons Attribution 4.0 International License, which permits use, sharing, adaptation, distribution and reproduction in any medium or format, as long as you give appropriate credit to the original author(s) and the source, provide a link to the Creative Commons licence, and indicate if changes were made. The images or other third party material in this article are included in the article's Creative Commons licence, unless indicated otherwise in a credit line to the material. If material is not included in the article's Creative Commons licence and your intended use is not permitted by statutory regulation or exceeds the permitted use, you will need to obtain permission directly from the copyright holder. To view a copy of this licence, visit http://creativecommons.org/licenses/by/4.0/.
\end{abstract}

(c) The Author(s) 2021 